Syntax Literate: Jurnal Ilmiah Indonesia p-ISSN: 2541-0849

e-ISSN: 2548-1398

Vol. 5, No. 11, November 2020

\title{
PENGARUH REWARD DAN INSENTIF TERHADAP KEPUASAN KERJA AGEN PLATINUM DI WILAYAH DKI JAKARTA
}

\author{
Alfonsus B. Say dan Erwin Rasyid
}

Sekolah Tinggi Ilmu Ekonomi (STIE) Unisadhuguna Jakarta Jawa Barat, Indonesia

Email: alfons.bsay@ubs-usg.ac.id dan erwin.rasjid@ubs-usg.ac.id

\section{Abstract}

This study aims to analyze the effect of rewards and incentives on the satisfaction of platinum agents in one of the insurance companies in DKI Jakarta. This research including in the category of quantitative descriptive research. This study uses individuals for the unit of analysis, answering questions based on responses from individuals who are included in the platinum agent category in the DKI Jakarta area. The type of data used is primary data. The population in this study was all platinum agents in DKI Jakarta, totaling 20 people. Because the population is small, all members of the population are made respondents or it is often said by the census. The research instrument used a questionnaire with a Likert scale. Data analysis includes validation and reliability tests. Statistical analysis using multiple linear regression test, coefficient of determination test, partial test (t-test), and simultaneous test ( $F$ test). The results showed that the reward has a partial effect on platinum agent satisfaction in the DKI Jakarta area. Likewise, incentives have a partial effect on platinum agent satisfaction in the DKI area. Simultaneously, rewards and incentives affect platinum agent satisfaction in the DKI Jakarta area.

Keywords: Reward; Incentive; Job Satisfaction; Insurance Agent

\section{Abstrak}

Penelitian ini bertujuan untuk menganalisis pengaruh reward dan insentif terhadap kepuasan agen platinum salah satu peusahaan asuransi di DKI Jakarta. Penelitian ini termasuk dalam kategori penelitian deskriptif kuantitatif. Penelitian ini menggunakan individu untuk unit analisisnya, menjawab pertanyaan berdasarkan tanggapan dari individu yang termasuk dalam kategori agen platinum di wilayah DKI Jakarta. Jenis data yang digunakan adalah data primer. Populasi dalam penelitian ini adalah seluruh agen platinum di wilayah DKI Jakarta yang berjumlah 20 orang. Karena jumlah populasinya kecil, maka semua anggota populasi dijadikan responden atau sering dikatakan dengan sensus. Instrumen penelitian menggunakan kuesioner dengan skala likert. Analisis data meliputi uji validasi dan reliabilitas. Analisis statistik menggunakan uji regresi linier berganda, uji koefisien determinasi, uji parsial (uji t), dan uji simultan (uji F). Hasil penelitian menunjukkan bahwa reward berpengaruh secara parsial terhadap kepuasan agen platinum di wilayah DKI Jakarta. Demikian juga dengan insentif, berpengaruh secara parsial terhadap kepuasan agen platinum di wilayah DKI. Secara simultan, reward dan insentif berpengaruh terhadap kepuasan agen platinum di wilayah DKI 
Jakarta. Penelitian ini juga menunjukan bahwa insentif yang diberikan perusahaan lebih berpengaruh terhadap kepuasan kerja agen platinum.

Kata kunci: Reward; Insentif; Kepuasan Kerja; Agen Asuransi

\section{Pendahuluan}

Perkembangan asuransi dewasa ini sangat pesat. Sebagian besar masyarakat Indonesia sudah mengenal peranan asuransi dalam kehidupan mereka, terlebih masyarakat kota Jakarta. Secara umum dapat dikatakan bahwa kegiatan perusahaan asuransi merupakan usaha yang berdasar pada kepercayaan masyarakat. Sehingga mau tidak mau, suka tidak suka, setiap perusahaan asuransi harus terus berbenah dalam rangka berkompetisi untuk mendapatkan kepercayaan dalam masyarakat. Profesionalisme dan kredibilitas perusahaan sangat dituntut agar dapat mencapai tujuan secara efektif dan efisien (Suryani, 2012). Untuk itu perusahaan harus mempersiapkan sumber daya manusia yang profesional dan kredibel agar mendapat tempat di hati masyarakat (Haseena, 2014). Tenaga kerja atau sumber daya manusia merupakan salah satu faktor produksi yang sangat memengaruhi keberhasilan suatu perusahaan dan tidak bisa disamakan dengan faktor produksi lainnya (Ranupandojo \& Husnan, 2002). Sehingga, pengelolaan sumber daya manusia harus disiapkan sebaik mungkin. Perhatian khusus harus diberikan perusahaan kepada sumber daya manusianya agar mereka memberikan prestasi secara totalitas kepada perusahaan (Suwatno \& Priansa, 2011). Mengelola dan mengatur tenaga kerja menjadi seni tersendiri bagi perusahaan pada umumnya, dan perusahaan asuransi khususnya (Suryani, 2012).

Fungsi manajemen sumber daya manusia meliputi perencanaan, pengorganisasian, pengarahan, serta pengawasan, termasuk didalamnya kegiatan pengadaan, pengembangan, kompensasi, integrasi, pemeliharaan tenaga kerja (Zenah, 2014). Keinginan perusahaan atas profesionalisme dan kinerja yang baik dari tenaga kerjanya sangat berkaitan dengan bagaimana suatu perusahaan mampu memberikan penghargaan terhadap tenaga kerjanya tersebut (Nawawi, 2018). Karena kualitas sumber daya manusia merupakan gambaran perlakuan yang diberikan suatu perusahaan kepada karyawannya, baik secara langsung maupun tidak langsung dan memiliki pengaruh terhadap kinerja perusahaan (Hasibuan, 2013).

Salah satu sumber daya manusia suatu perusahaan asuransi adalah agen asuransi. Walaupun peran agen asuransi sangat besar terhadap pendapatan perusahaan, akan tetapi agen asuransi tidak memiliki kontrak yang mengikat terhadap perusahaan asuransi, yang menyebabkan hak atau benefit yang didapat oleh seorang agen asuransi berbeda dengan karyawan perusahaan asuransi. Agen asuransi tidak mendapat gaji seperti yang didapat karyawan, melainkan hanya komisi atas penjualan mereka. Bentuk insentif yang didapat adalah perjalanan wisata luar negeri yang dibuat dalam bentuk sebuah kontes untuk para agen jika mencapai suatu target tertentu (Fuad, Iskandar, Sendra, \& Wirasadi, 2010). Bentuk reward yang didapat oleh seorang agen asuransi adalah mendapat undangan khusus untuk menghadiri acara penghargaan atau awarding event. Acara penghargaan tersebut merupakan bentuk penghargaan dari perusahaan 
asuransi kepada para agen platinum yang telah mencapai target tertentu yang telah dikonteskan. Perusahaan mengharapkan dari pemberian reward dan insentif tersebut dapat meningkatkan kinerja dan loyalitas mereka untuk perusahaan asuransi.

Salah satu perusahaan asuransi yang terbilang sering mengadakan acara penghargaan adalah PT XY. Perusahaan ini memisahkan pengelolaan manajemennya untuk asuransi jiwa dan asuransi umum. Pada penelitian ini hanya akan memfokuskan pada agen platinum asuransi umum sebagai obyek penelitian.

Perusahaan memiliki lebih dari seratus agen yang bersertifikasi. Untuk agen yang telah mengumpulkan premi terbanyak dan loyal terhadap perusahaan termasuk kategori agen platinum. Total agen platinum perusahaan sebanyak 20 orang. Agen platinum memiliki perlakuan sedikit berbeda dengan tenaga penjual lainnya atau business partner lainnya. Hal ini dikarenakan perusahaan mendapatkan premi terbesar dari agen platinum tersebut. Agen platinum bekerja dengan komisi, tanpa mendapatkan gaji tetap dan tunjangan. Padahal, di sisi lain agen platinum tersebut mengeluarkan biaya untuk menjalankan bisnis, transportasi, modul, seminar, maupun untuk memelihara hubungan baik dengan nasabah asuransi. Sehingga perusahaan memberikan apresiasi lebih kepada para agen platinum dengan mengadakan acara malam penghargaan tiap tahunnya dengan nama acara "Agency Awards Night". Dengan diselenggarakan acara ini, perusahaan berharap dapat meningkatkan kinerja para agen platinumnya, yang pada akhirnya akan meningkatkan kinerja perusahaan.

Beberapa penelitian yang sudah dilakukan mengenai pengaruh reward terhadap kepuasan kerja menunjukan bahwa reward tidak berpengaruh signifikan positif terhadap job satisfaction karyawan Bank, seperti penelitian yang sudah dilakukan oleh Fausta Hindarti dan Amin Wahyudi, 2015 dan Yohanas Oemar. Akan tetapi beberapa penelitian lain menunjukan bahwa reward berpengaruh secara positif dan signifikan terhadap kepuasan kerja karyawan industri lainnya.

Dari beberapa penelitian yang sudah penulis baca, menunjukan bahwa insentif berpengaruh positif dan signifikan terhadap kepuasan kerja karyawan, seperti penelitian yang dilakukan oleh Priambada, Bangkit. (2011), Zenah, Syarifah Nur. (2014), Huang, Chen Jung, \& Hsueh, Sue Chen. (2014), dan beberapa penelitian lainnya.

Dari latar belakang yang telah penulis paparkan di atas, juga dari beberapa penelitian yang sudah dilakukan, penulis mencoba melakukan penelitian mengenai pengaruh reward dan insentif terhadap kepuasan kerja karyawan di bidang asuransi yang dalam hal ini adalah agen platinum. Tujuan penelitian ini untuk mengetahui apakah reward dan insentif berpengaruh terhadap kepuasan kerja, baik secara parsial maupun simultan. Diharapkan hasil penelitian ini dapat berguna bagi perusahaan asuransi dalam mengelola pemberian reward dan insentifnya.

\section{Metode Penelitian}

Pengumpulan data dilakukan dengan 2 (dua) cara, yaitu dengan menyebarkan kuesioner (daftar pertanyaan) kepada 20 (dua puluh) orang agen platinum dengan harapan dapat memberikan respon terhadap daftar pertanyaan tersebut. Kuesioner 
disusun menggunakan skala likert. Cara pengumpulan data berikutnya adalah dengan studi kepustakaan, serta dokumen-dokumen yang diperoleh di lokasi penelitian.

Setelah data-data yang diperlukan didapat, langkah selanjutnya adalah dengan melakukan uji intrumen. Dalam langkah ini dilakukan dalam 2 (dua) tahap pengujian, yaitu uji validitas dan uji reliabilitas. Untuk menguji validitas kuesioner digunakan rumus korelasi Product Moment Pearson. Sedangkan uji reliabilitas menggunakan alat ukur dengan rumus Alpha Cronbach (Arikunto, 2016). Dengan Interpretasi koefisien Korelasi r sebagai berikut (Sugiyono, 2016):

\section{Tabel 1}

Interpretasi Koefisien Korelasi Nilai $\mathbf{r}$

\begin{tabular}{cl}
\hline Interval Koefisien & Tingkat Hubungan \\
\hline $0,80-1,000$ & Sangat Kuat \\
$0,60-0,799$ & Kuat \\
$0,40-0.599$ & Cukup Kuat \\
$0,20-0,399$ & Rendah \\
$0,00-0,199$ & Sangat Rendah \\
\hline
\end{tabular}

Pengujian berikutnya adalah pengujian parameter, meliputi uji parameter individual (uji statistik t) bertujuan untuk mengukur seberapa jauh pengaruh satu variabel independen secara individual dalam menerangkan variasi variabel dependen dan uji parameter secara simultan. Dan yang terakhir adalah pengujian best of fit model.

\section{Hasil dan Pembahasan}

Penelitian yang menggunakan kuesioner / angket, terlebih dahulu harus dilakukan uji instrumen, yang terdiri dari:

\section{Uji Instrumen}

a. Uji Validitas

Hasil uji validitas variabel independen penelitian dapat dilihat pada Tabel 2 berikut.

\section{Tabel 2}

Hasil Uji Validitas Variabel Reward $\left(\mathrm{X}_{1}\right)$

\begin{tabular}{cccc}
\hline \multirow{2}{*}{ Pernyataan } & Koefisien Korelasi & Sig & Keterangan \\
& & & Valid \\
\hline Butir 1 & 0,544 & 0,007 & Valid \\
\hline Butir 2 & 0,573 & 0,004 & Valid \\
\hline Butir 3 & 0,463 & 0,020 & Valid \\
\hline Butir 4 & 0,436 & 0,027 & Valid \\
\hline Butir 5 & 0,522 & 0,009 & Valid \\
\hline Butir 6 & 0,461 & 0,020 & Valid \\
\hline Butir 7 & 0,421 & 0,032 & Tidak Valid \\
\hline Butir 8 & 0,199 & 0,200 & Valid \\
\hline Butir 9 & 0,439 & 0,026 & Valid
\end{tabular}

Sumber: Hasil Olah Data (SPSS 22)

Dari Tabel 2 di atas dapat diketahui bahwa untuk items pernyataan variabel reward yang tingkat signifikannya $<0,05$ dan tingkat korelasinya $>0,4$ 
dapat dinyatakan bahwa pernyataan butir pertama, kedua, ketiga, keempat, kelima, keenam, ketujuh, kesembilan, dan kesepuluh adalah valid. Sedangkan, pernyataan butir kedelapan dihilangkan karena tidak valid. Hal dikarenakan tingkat signifikannya $>0,05$ dan tingkat korelasinya $<0,4$, sehingga dinyatakan tidak valid.

\section{Tabel 3}

Hasil Uji Validitas Variabel Insentif $\left(\mathbf{X}_{2}\right)$

\begin{tabular}{cccc}
\hline Pernyataan & Koefisien Korelasi & Sig & Keterangan \\
\hline Butir 1 & 0,843 & 0,000 & Valid \\
\hline Butir 2 & 0,460 & 0,021 & Valid \\
\hline Butir 3 & 0,880 & 0,000 & Valid \\
\hline Butir 4 & 0,880 & 0,000 & Valid \\
\hline Butir 5 & 0,563 & 0,005 & Valid \\
\hline & Sumber: Hasil olah data menggunakan SPSS 22.0 &
\end{tabular}

Dari Tabel 3 di atas dapat diketahui bahwa untuk items pernyataan variabel insentif yang tingkat signifikannya $<0,05$ dan tingkat korelasinya $>0,4$ maka dapat dinyatakan bahwa secara keseluruhan items pernyataan tersebut adalah valid.

Tabel 4

Hasil Uji Validitas Variabel Kepuasan Kerja Agen Platinum (Y)

\begin{tabular}{cccc}
\hline Pernyataan & Koefisien Korelasi & Sig & Keterangan \\
\hline Butir 1 & 0,836 & 0,000 & Valid \\
\hline Butir 2 & 0,770 & 0,000 & Valid \\
\hline Butir 3 & 0,747 & 0,000 & Valid \\
\hline Butir 4 & 0,638 & 0,001 & Valid \\
\hline Butir 5 & 0,708 & 0,000 & Valid \\
\hline
\end{tabular}

Sumber: Hasil olah data SPSS 22.0

Dari Tabel 4 di atas dapat diketahui bahwa untuk items pernyataan variabel kepuasan kerja agen platinum yang tingkat signifikannya $<0,05$ dan tingkat korelasinya > 0,4 maka dapat dinyatakan bahwa secara keseluruhan items pernyataan tersebut adalah valid.

b. Uji Reliabilitas

Hasil penelitian menunjukan bahwa semua variabel penelitian reliabel. Hal ini ditunjukkan pada Tabel 5 di bawah ini.

Tabel 5

Hasil Uji Reliabilitas Variabel-Variabel Penelitian

\begin{tabular}{cccc}
\hline Variabel & $\begin{array}{c}\text { Cronbach's } \\
\text { Alpha }\end{array}$ & $\begin{array}{c}\text { Reliabilitas } \\
\text { Minimum }\end{array}$ & Keterangan \\
\hline Reward $\left(\mathrm{X}_{1}\right)$ & 0,644 & 0,600 & Reliabel \\
\hline Insentif $\left(\mathrm{X}_{2}\right)$ & 0,790 & 0,600 & Reliabel \\
\hline $\begin{array}{c}\text { Kepuasan Kerja } \\
\text { Agen Platinum }(\mathrm{Y})\end{array}$ & 0,791 & 0,600 & Reliabel \\
\hline
\end{tabular}


Dari hasil pengujian reliabilitas, diperoleh hasil nilai koefisien alfa (Cronbach's Alpha) untuk semua variabel adalah > 0,600. Sehingga dapat disimpulkan bahwa semua variabel reliabel.

\section{Uji Hipotesi}

a. Uji $t$

Hasil uji t penelitian ini dapat dilihat pada Table 6 berikut.

Tabel 6 Hasil Uji t

Coefficients $^{\mathrm{a}}$

\begin{tabular}{|c|c|c|c|c|c|c|}
\hline & \multirow[b]{2}{*}{ Model } & \multicolumn{2}{|c|}{ Unstandardized Coefficients } & $\begin{array}{l}\text { Standardized } \\
\text { Coefficients } \\
\end{array}$ & \multirow[b]{2}{*}{$\mathrm{t}$} & \multirow[b]{2}{*}{ Sig. } \\
\hline & & $\mathrm{B}$ & Std. Error & Beta & & \\
\hline \multirow[t]{3}{*}{1} & (Constant) & -.650 & 3.886 & & -.167 & .869 \\
\hline & Reward & .291 & .137 & .395 & 2.126 & .048 \\
\hline & Insentif & .461 & .177 & .484 & 2.609 & .018 \\
\hline
\end{tabular}

Sumber: Hasil olah data menggunakan SPSS 22.0

Dari Tabel 6 di atas dapat dijelaskan sebagai berikut:

1) Dengan membandingkan nilai $t_{h i t u n g}$ dengan nilai tabel. Hasilnya $2,126>$ 2,10982, maka variabel reward $\left(\mathrm{X}_{1}\right)$ mempunyai pengaruh yang signifikan terhadap variabel kepuasan kerja agen platinum (Y).

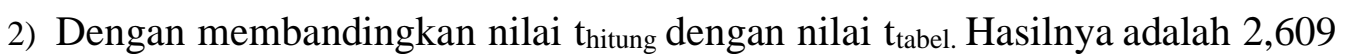
$>$ 2,10982, maka variabel insentif $\left(\mathrm{X}_{2}\right)$ mempunyai pengaruh yang signifikan terhadap variabel kepuasan kerja agen platinum (Y).

b. Uji $F$

Hasil uji F penelitian ini dapat dilihat pada Table 7 berikut.

\section{Tabel 7}

Hasil Uji Simultan (Uji F)

\begin{tabular}{|c|c|c|c|c|c|c|}
\hline & \multicolumn{6}{|c|}{ ANOVA $^{a}$} \\
\hline & Model & $\begin{array}{c}\text { Sum of } \\
\text { Squares }\end{array}$ & df & $\begin{array}{c}\text { Mean } \\
\text { Square }\end{array}$ & $\mathrm{F}$ & Sig. \\
\hline 1 & Regression & 41.635 & 2 & 20.818 & 13.526 & $.000^{\mathrm{b}}$ \\
\hline & Residual & 26.165 & 17 & 1.539 & & \\
\hline & Total & 67.800 & 19 & & & \\
\hline
\end{tabular}

Sumber: Hasil olah data menggunakan SPSS 22.0

Berdasarkan Tabel 7 di atas dapat diketahui bahwa nilai $F_{\text {hitung }}$ adalah 13,526. Sedangkan, untuk jumlah sampel 20 dan dua variabel bebas yang diteliti, maka besarnya nilai $F_{\text {tabel }}$ adalah 3,59. Dengan membandingkan nilai $F_{\text {hitung }}$ dengan nilai $F_{\text {tabel}}$, yaitu $13,526>3,59$, maka dapat disimpulkan terdapat pengaruh yang signifikan antara variabel reward $\left(\mathrm{X}_{1}\right)$ dan insentif $\left(\mathrm{X}_{2}\right)$ secara simultan terhadap variabel kepuasan kerja agen platinum (Y).

\section{Koefisien Determinasi}

Nilai koefisien determinasi penelitian dapat dilihat pada tabel di bawah ini: 


\begin{tabular}{|c|c|c|c|c|}
\hline & & $\begin{array}{r}\text { Tal } \\
\text { oefisien }\end{array}$ & $\begin{array}{l}18 \\
\text { eteminasi }\end{array}$ & \\
\hline Model & $\mathrm{R}$ & R Square & $\begin{array}{c}\text { Adjusted R } \\
\text { Square }\end{array}$ & $\begin{array}{c}\text { Std. Error of the } \\
\text { Estimate }\end{array}$ \\
\hline 1 & $.784^{\mathrm{a}}$ & .614 & .569 & 1.24060 \\
\hline
\end{tabular}

Berdasarkan Tabel 8 dapat disimpulkan bahwa nilai R Square sebesar 0.614, artinya bahwa variable Reward dan variable Insentif secara bersama-sama mampu menjelaskan variabel Kepuasan Kerja sebesar 61,4\% sedangkan, sisanya sebesar $38,6 \%$ adalah faktor - faktor lain yang tidak diteliti dalam penelitian ini.

\section{Analisis Regresi Linear Berganda}

Dari Tabel 6, didapat persamaan regresi linear berganda penelitian, yaitu:

$$
\mathrm{Y}=-0.650+0.291 \mathrm{X}_{1}+0.461 \mathrm{X}_{2} \text {. }
$$

Dimana:

$\mathrm{X}_{1}=$ Reward

$\mathrm{X}_{2}=$ Insentif

$\mathrm{Y}=$ Kepuasan Kerja

Dapat dijelaskan sebagai berikut:

a. Nilai konstanta (koefisien intersep) sebesar - 0.650 menyatakan bahwa jika variabel Reward $\left(\mathrm{X}_{1}\right)$ dan variabel Insentif $\left(\mathrm{X}_{2}\right)$ nol maka nilai variabel Kepuasan Kerja agen platinum (Y) adalah sebesar -0.650.

b. Nilai koefisien regresi variabel Reward $\left(\mathrm{X}_{1}\right)$ terhadap variabel Kepuasan Kerja (Y) adalah sebesar 0.291. Hal ini berarti jika variabel Reward $\left(\mathrm{X}_{1}\right)$ naik sebesar $1 \%$, akan meningkatkan variabel Kepuasan Kerja (Y) sebesar 0.291, dengan asumsi variabel Insentif $\left(\mathrm{X}_{2}\right)$ dan konstanta dianggap tetap. Hal ini berarti semakin baik dan meningkatnya reward yang diterima maka semakin meningkat pula kepuasan kerja agen platinum. Hasil ini relevan dengan jawaban dari responden yang diperoleh melalui penyebaran kuisioner kepada 20 responden menunjukkan program insentif agen platinum di PT. X baik. Hasil ini berdasarkan analisis rentang skala yang didapatkan hasil secara ratarata program insentif berada pada range baik. Hasil penelitian ini sejalan dengan hasil penelitian-penelitian sebelumnya yang dilakukan oleh, Sriratanaprapat \& Songwathana, 2011, (Priambada, 2011) dan (Huang \& Hsueh, 2014), menunjukkan bahwa pengalaman dan faktor-faktor kepuasan kerja gaji, promosi, tunjangan dan imbalan kontingen yang ditemukan terkait positif dengan kepuasan kerja. Bentuk reward yang didapat oleh seorang agen platinum pada PT. X berupa undangan khusus untuk menghadiri acara penghargaan atau awarding event. Acara penghargaan tersebut merupakan bentuk penghargaan dari perusahaan asuransi kepada para agen platinum yang telah mencapai target tertentu yang telah dikonteskan yang tidak diberikan 
kepada agen lainnya. Bentuk reward ini sudah sesuai dengan harapan sebagian besar agen platinum. Hal ini dibuktikan dengan akan meningkatnya kepuasan kerja agen platinum, jika reward yang mereka terima meningkat.

c. Nilai koefisien regresi variabel Insentif $\left(\mathrm{X}_{2}\right)$ terhadap variabel Kepuasan Kerja (Y) adalah sebesar 0.461 . Hal ini berarti jika variabel Insentif $\left(\mathrm{X}_{2}\right)$ naik sebesar 1 persen, maka hal tersebut akan meningkatkan variabel Kepuasan Kerja (Y) sebesar 0.461 persen, dengan asumsi bahwa variabel Reward $\left(\mathrm{X}_{1}\right)$ dianggap konstan atau tidak berubah. Hasil ini relevan dengan jawaban dari responden yang diperoleh melalui penyebaran kuisioner kepada 20 responden yang menunjukkan program insentif agen platinum di PT. X berada pada range baik. Insentif adalah bentuk imbalan atau balas jasa yang diberikan oleh suatu organisasi atau perusahaan kepada pegawai dalam bentuk materi (material insentive) maupun dalam bentuk kepuasan rohani (non material insentif). Insentif merupakan bentuk lain dan imbalan langsung di luar gaji yang merupakan imbalan tetap, biasanya sistem ini diutamakan sebagai strategi untuk meningkatkan produktifitas pegawai. Insentif atau bonus merupakan salah satu cara untuk meningkatkan motivasi kerja dan kinerja pegawai (Ruky, 2012). Bentuk insentif yang diberikan PT. X kepada agen platinumnya berupa perjalanan wisata ke luar negeri yang dibuat dalam bentuk sebuah kontes jika mencapai suatu target tertentu. Dan insentif ini hanya diberikan kepada agen platinum diluar komisi penjualan dan komisi pencapaian target. Bentuk insentif ini sudah sesuai dengan harapan para agen platinum, hal ini dibuktikan dengan kenaikan nilai kepuasan kerja, jika terjadi kenaikan insentif.

\section{Kesimpulan}

Hasil penelitian menunjukan ada pengaruh positif dan signifikan pemberian reward terhadap kepuasan kerja agen platinum. Semakin tinggi reward yang diterima, maka tingkat kepuasan kerja agen platinum juga akan semakin tinggi yang pada akhirnya akan meningkatkan produktivitas agen platinum dan kinerja perusahaan.

Ada pengaruh positif dan signifikan insentif terhadap kepuasan kerja agen platinum. Semakin besar/tinggi insentif yang diberikan perusahaan kepada agen platinum, maka akan semakin tinggi pula tingkat kepuasan kerjanya. Hal ini akan berpengaruh kepada produktivitas sang agen platinum yang juga akan memberikan dampak positif pada kinerja perusahaan yang didapat melalui profitnya. Bagi peneliti selanjutnya penulis menyarankan untuk lebih mendalami, faktor apa yang menyebabkan reward lebih rendah dari insentif pengaruhnya terhadap kepuasan kerja agen platinum

Dari hasil perhitungan regresi linier berganda, diantara 2 (dua) variabel reward dan insentif, didapat bahwa insentif lebih dominan pengaruhnya pada kepuasan kerja agen platinum. Sehingga perusahaan sebaiknya lebih memberikan perhatian lebih kepada pemberian insentif. Bagi peneliti yang akan melakukan penelitian selanjutnya bisa melakukan penelitian mengenai jenis insentif apa yang paling berpengaruh terhadap kepuasan kerja agen platinum. 
Pengaruh Reward dan Insentif Terhadap Kepuasan Kerja Agen Platinum di Wilayah

DKI Jakarta

\section{BIBLIOGRAFI}

Arikunto, Suharsimi. (2016). Prosedur Penelitian Suatu Pendekatan Praktis. Jakarta: PT Rineka Cipta.

Fausta Hindarti dan Amin Wahyudi, (2015). Pengaruh Reward Terhadap Kepuasan Kerja Dengan Motivasi Sebagai Variabel Mediasi (Studi Pada Karyawan PT Bank Central Asia Tbk. Cabang Utama Surakarta). Surakarta. Jurnal Ekonomi Dan Kewirausahaan Volume 15, Nomor 3

Fuad, Noor, Iskandar, Kasir, Sendra, Ketut, \& Wirasadi, Faustinus. (2010). DasarDasar Asuransi Jiwa dan Asuransi Kesehatan. Jakarta: Bidang Penelitian dan Pengembangan Asosiasi Ahli Manajemen Asuransi Indonesia.

Haseena, Anisa. (2014). Pengertian Asuransi dan Jenis-Jenisnya Serta Contoh Perusahaan Asuransi. Retrieved from wordpress.com website: https://anisahaseena.wordpress.com/2014/09/24/pengertian-asuransi-dan-jenisjenisnya-serta-contoh-perusahaan-asuransi/

Hasibuan, Malayu S. P. (2013). Manajemen Sumber Daya Manusia, Cetakan ke-17. Jakarta: PT Bumi Aksara.

Huang, Chen Jung, \& Hsueh, Sue Chen. (2014). A study of the effect of incentive system on job performance-an example of hotel's IT staffs in Taiwan. Journal of Global Business Management, 10(2), 57.

Mukhtar, P. D. (2013). Metode Praktis Penelitian Deskriptif Kualitatif. Jakarta: GP Press Group.

Nawawi, H. Hadari. (2018). Manajemen Sumber Daya Manusia Untuk Bisnis yang Kompetitif. Yogyakarta: Gadjah Mada University Press.

Priambada, Bangkit. (2011). Pengaruh Pemberian Insentif terhadap Kinerja Karyawan (Studi pada AJB BUMIPUTERA 1912 Kantor Cabang Kayutangan, Malang). Universitas Brawijaya Malang.

Ranupandojo, Heidjrachman, \& Husnan, Suad. (2002). Manajemen Personalia. Yogyakarta: BPFE.

Ruky, Achmad S. (2012). Manajemen Penggajian dan Pengupahan Untuk Karyawan Perusahaan. Jakarta: Gramedia Pustaka Utama.

Sriratanaprapat, Jarurat, \& Songwathana, Praneed. (2011). Nurses' job satisfaction within the context of Asian cultures: a concept analysis. Pacific Rim International Journal of Nursing Research, 15(1), 57-73.

Sugiyono. (2016). Metode Penelitian Kuantitatif, Kualitatif Dan R\&D. Bandung: Alfabeta. 
Alfonsus B. Say dan Erwin Rasyid

Suryani, Devi. (2012). Hubungan Pemberian Insentif Terhadap Kinerja Agen Penjualan Polis Asuransi Pada PT. Asuransi Bintang Tbk Cabang Pekan Baru. Riau. Skripsi.

Suwatno, H., \& Priansa, Donni Juni. (2011). Manajemen SDM dalam organisasi Publik dan Bisnis. Bandung: Alfabeta.

Zenah, Syarifah Nur. (2014). Hubungan Pemberian Insentif Dengan Motivasi Kerja Perawat Ruang Rawat Inap Kelas III RSUD Inche Abdul Moeis Samarinda. EJournal Administrasi Negara, 3(2), 451-463. 